\title{
ANALISIS PENDAPATAN USAHATANI SAYURAN DI KELOMPOK TANI JAYA, DESA CIARUTEUN ILIR, KECAMATAN CIBUNGBULANG, KABUPATEN BOGOR
}

\author{
Dodi Normansyah*, Siti Rochaeni**, Armaeni Dwi Humaerah**
}

\begin{abstract}
ABSTRAK
Penelitian ini dilakukan untuk menganalisis tingkat pendapatan dan efisiensi dari usahatani sayuran di kelompok Tani Jaya Desa Ciaruteun Ilir, adapun jenis sayuran yang menjadi fokus dalam penelitian ini adalah bayam, kangkung, dan caisim. Penelitian ini menggunakan analisis pendapatan usahatani, analisis $R / C$ ratio (Return Ana Cost ratio) yaitu analisis perbandingan antara penerimaan dan pengeluaran usahatani, analisis $B / C$ ratio (Benefit and Cost ratio) yaitu analisis tingkat keuntungan dibandingkan dengan biaya usahatani, serta analisis BEP (Break Even Point) yaitu analisis titik impas. Data yang digunakan dalam penelitian didapatkan dari wawancara langsung kepada petani yang tergabung dalam kelompok tani Jaya Desa Ciaruteum Ilir dan ditambahkan dengan data pendukung lain yang dapat menunjang dari studi literatur dan pustaka. Hasil dari penelitian ini menunjukkan bahwa pendapatan usahatani dari kelompok tani Jaya Desa Ciaruteum Ilir sebesar Rp. 3.649.993/Ha/tahun/petani dan usahatani sayuran ini dinilai layak untuk dijalankan dan berprospek bagus untuk dikembangkan. Saran yang bisa diajukan setelah dilakukan penelitian ini adalah: 1) Data hasil penelitian menunjukkan bahwa usahatani sayuran di kelompok Tani Jaya ini sangat menguntungkan dan efektif, hal tersebut juga menunjukkan bahwa usahatani sayuran ini mempunyai prospek yang bagus untuk dikembangkan dengan cara penambahan luas area tanam. Dengan bertambahnya luas areal serta pengelolaan yang bagus akan meningkatkan produksi dan diikuti dengan bertambahnya pendapatan petani. 2) Disarankan ada pelatihan manajemen yang baik terhadap para anggota kelompok tani. Baik itu pelatihan mengenai teknis usahatani maupun non teknis seperti pelatihan menganalisis usahatani dengan baik. Hasil analisis ini bisa dimanfaatkan untuk pengembangan usahatani terutama untuk mendapatkan pembiayaan dari lembaga peminjam modal.
\end{abstract}

Kata kunci : biaya usahatani, pendapatan usahatani, sayuran 


\begin{abstract}
This study is conducted to analyze level of income and efficiency of vegetables farming in Jaya farmers groups, Ciaruteun Ilir village, as for the type of vegetables that become the focus of this research are spinach, water spinach, and caisim. This study uses analysis of farm income, analysis of $R / C$ ratio (Return and Cost Ratio) which is a comparative analysis between revenue and expenditure of farming, analysis of $B$ / C ratio (Benefit and Cost Ratio) which is the analysis of the rate of profit compared with the cost of farming, as well as analysis of BEP (Break Even point) which is a break-even analysis. Data used in the study are obtained from interviews to farmers in Jaya farmer groups Ciaruteum Ilir village and added with other supporting data that can support from literature. The results of this study indicate that farm income of Jaya farmer groups Ciaruteum Ilir village is Rp. 3,649,993/ha / year/farmer and vegetable farming is considered feasible and it has good prospects for development. Some important suggestions are: 1) Data results show that vegetable farming in Jaya farmers group is very beneficial and effective, it also shows that vegetable farming has a good prospect to be developed by the addition of area planted. With increasing acreage and good management, it will increase production and followed with increasing in farmers' income. 2) It is recommended that a good management training to members of farmer groups whether on technical or non-technical farming. The results of this analysis can be used for the development of farming especially to get financing from a lending institution capital.
\end{abstract}

Keywords: costs of farming, farm income, vegetables

\section{PENDAHULUAN}

Pertanian merupakan mata pencarian utama bagi mayoritas penduduk Indonesia. Dari 112,8 juta penduduk Indonesia yang bekerja, 41,20 juta jiwa bekerja di bidang pertanian (BPS, 2012). Sektor pertanian meliputi berbagai subsektor seperti hortikultura, tanaman pangan, perkebunan, perikanan, peternakan, dan kehutanan. Salah satu subsektor pertanian yang menjadi andalan adalah hortikultura. Produk hortikultura yang meliputi tanaman sayuran, tanaman buah-buahan, tanaman obat, dan tanaman hias mempunyai kontribusi yang besar terhadap manusia dan lingkungan. Dari ketiga jenis produk hortikultura, sayuran memiliki manfaat yang besar bagi kehidupan manusia diantaranya sebagai sumber pangan dan gizi, pendapatan keluarga, dan pendapatan negara. (Ashari, 1995:171).

Produk sayuran memiliki peluang yang baik di pasaran karena jumlah konsumsi penduduk Indonesia dari tahun ketahun akan terus meningkat seiring dengan tingginya pertumbuhan jumlah penduduk dari tahun ke tahun. Setiap lima tahun penduduk Indonesia bertambah kurang lebih sekitar 14 juta jiwa. Data di 
lapangan menunjukkan, dari tahun 2005 sampai tahun 2010 tingkat konsumsi penduduk Indonesia akan sayuran mengalami peningkatan secara fluktuatif seperti yang terlihat pada tabel di bawah ini:

Tabel 1Tingkat Konsumsi Sayuran Indonesia Tahun 2005-2010

\begin{tabular}{cccc}
\hline No & Tahun & $\begin{array}{c}\text { Tingkat } \\
\text { Konsumsi } \\
(\mathrm{Kg} / \text { kapita/thn })\end{array}$ & $\begin{array}{c}\text { Rekomendasi } \\
\text { FAO } \\
(\text { Kg/kapita/thn })\end{array}$ \\
\hline 1 & 2005 & 35.30 & \\
2 & 2006 & 34.06 & \\
3 & 2007 & 40.90 & 73 \\
4 & 2008 & 36.50 & \\
5 & 2009 & 40.10 & \\
6 & 2010 & 41.90 & \\
\hline
\end{tabular}

Sumber: Kementrian Pertanian RI 2011

Peluang pengembangan produk sayuran diikuti dengan penyebaran luas area produksi sayuran. Salah satu produsen sayuran dengan produksi dalam jumlah besar adalah Desa Ciaruteun Ilir yang terletak di Kecamatan Cibungbulang, Kabupaten Bogor. Tanaman sayuran merupakan jenis komoditi yang memiliki nilai ekonomi tinggi dan berperan penting dalam pemenuhan berbagai kebutuhan keluarga petani. Penyuluh pertanian Kecamatan Cibungbulang menyebutkan bahwa produksi sayuran di Desa Ciaruteun Ilir dari semua jenis sayuran mencapai 2550 ton perhari atau 10-25 mobil perhari yang membawa sayuran dari desa ini ke tempat pemasaran.

Tujuan modernisasi pertanian adalah agar petani mampu melaksanakan usahatani-nya secara lebih produktif (better farming), lebih menguntungkan (better bussiness), meningkatkan taraf hidup masyarakat tani (better living), dan memperluas lapangan kerja (Samsudin, 1986: 138). Petani di kelompok Tani Jaya memiliki tujuan yang sejalan dengan tujuan pertanian modern seperti di atas, selalu berharap usahatani sayuran yang dikembangkan dapat memberikan jaminan penghidupan yang layak untuk keluarganya. Kehidupan yang layak itu tentu akan tecapai apabila usahatani sayuran ini memberikan kontribusi terhadap peningkatan pendapatan petani dalam jumlah besar. pendapatan yang cukup besar dalam ekonomi pertanian tidak bermakna bila harus didapatkan dengan menggunakan pencurahan biaya produksi dalam jumlah besar juga. Namun sebetulnya pilihanpilihan yang paling penting dilakukan petani adalah bagaimana memperoleh rasio yang cukup lebar antara pendapatan yang diperoleh dari kegiatan usahataninya bila dibandingkan dengan total biaya produksi yang telah dikeluarkan. Semakin besar rasio yang didapatkan maka semakin tepat pilihan-pilihan penggunaan sumberdaya yang dilakukan dalam kegiatan usahataninya. Untuk mengetahui rasio tersebut harus dilakukan perhitungan rinci tentang usahatani sayuran ini. Permasalahan yang timbul adalah petani Desa Ciaruteun Ilir umumnya dan kelompok Tani Jaya khususnya belum secara rinci melakukan analisis 
usahataninya. Hal tersebut perlu dilakukan oleh setiap usaha pertanian, mengingat pentingnya pencapaian tujuan peningkatan pendapatan dan dalam mengalokasikan sumber daya yang ada secara efektif dan efisien. Selain itu, untuk pengembangan lebih lanjut usahatani sayuran di Desa Ciaruteun Ilir ini perlu pembiayaan besar yang berasal dari infestor atau bank, pihakpihak penyalur dana tersebut memerlukan gambaran tentang keadaan usahatani sayuran yang akan dibiayainya salah satunya berupa analisis usahatani sayuran. Oleh karena itu, untuk mengetahui kelayakan usaha yang dijalankan maka perlu dilakukan analisis usahatani sayuran di kelompok Tani Jaya.

\section{Perumusan Masalah}

Berdasarkan latar belakang masalah yang telah diuraikan di atas, maka permasalahan yang akan dibahas dalam penelitian ini adalah sebagai berikut:

1. Berapakah tingkat pendapatan yang dihasilkan kelompok Tani Jaya Desa Ciaruteun Ilir?

2. Berapa $\mathrm{R} / \mathrm{C}$ ratio, $\mathrm{B} / \mathrm{C}$ ratio, dan Break Event Point (BEP) usahatani sayuran di kelompok Tani Jaya Desa Ciaruteun Ilir?

\section{Tujuan Penelitian}

Berdasarkan rumusan masalah, maka tujuan dari penelitian ini adalah sebagai berikut:

1. Menganalisis tingkat pendapatan usahatani sayuran di kelompok Tani Jaya Desa Ciaruteun Ilir.

2. Menganalisis tingkat efisiensi usahatani sayuran di Kelompok Tani Jaya Desa Ciaruteun Ilir.

\section{TINJAUAN PUSTAKA}

\section{Usahatani}

Menurut Suratiyah (2006), usahatani adalah pengusaha tani yang mengusahakan dan mengkoordinir faktor-faktor produksi berupa lahan dan alam sekitarnya sebagai modal sehingga memberikan manfaat yang sebaik-baiknya. Menurut Rahim dan Hastuti (2007:36), pada dasarnya usahatani memiliki unsur-unsur yang memiliki peranan yang sangat penting dalam kegiatan usahatani, yaitu lahan pertanian, tenaga kerja, modal dan manajemen.

\section{Sayuran}

Rihardi dkk (1993) mengemukakan bahwa sayuran merupakan komoditas hortikultura dan menjadi bagian dari menu makan keluarga Indonesia. Sayuran merupakan bahan makanan yang berasal dari tumbuh-tumbuhan (bahan makanan nabati). Bagian tumbuhan yang dapat dimakan dan dijadikan sayur adalah daun, batang, bunga dan buah, buah muda dan umbi. Sehingga dapat dikatakan bahwa semua bagian tumbuhan dapat dijadikan sayur (Sumoprastowo, 2000).

\section{Jenis-jenis Sayuran}


Banyak terdapat jenis sayuran seperti yang telah di jelaskan di atas, namun dalam penelitian ini peneliti memfokuskan pada beberapa jenis sayuran diantaranya adalah bayam, kangkung, dan caisim dengan pertimbangan bahwa semua jenis sayuran ini merupakan sayuran andalan petani dalam mengelola usahatani di Desa Ciaruteun Ilir secara umum dan petani anggota Kelompok Tani Jaya hususnya. Bayam termasuk tanaman gulma yang tumbuh liar karena digolongkan dalam keluarga Amaranthaceae dengan marga Amaranthus,. Namun karena perkembangannya, manusia memanfaatkan bayam sebagai tanaman budidaya dengan kandungan gizi tinggi (Hadisoeganda, 1996). Kangkung (Ipomoea reptans) berasal dari daerah tropis, terutama di kawasan Afrika dan Asia. Daerah penyebaran tanaman kangkung pada mulanya terpusat di beberapa tempat atau negara, antaralain di Malaysia dan sebagian kecil di Australia. Negara-negara yang membudidayakannya secara intensif dan komersial adalah Taiwan, Thailand, Filipina, dan Indonesia. Caisim ( Brassica chinensis L.) merupakan tanaman asli Asia. Caisim dibudidayakan di Cina Selatan dan Tengah, di negara-negara Asia Tenggara seperti Indonesia, Malaysia, Thailand, Vietnam, di bagian lain dari Indo-China, dan di beberapa bagian barat India.

\section{Kelompok Tani}

Kelompok tani merupakan bagian dari kelompok-kelompok sosial yang hidup dalam suatu masyarakat. Kelompok sosial menurut Bierstedt (1948) dalam Suharto (1993) adalah kumpulan individu yang memiliki kesadaran akan persamaan dan berhubungan satu sama lain, tetapi tidak terikat dalam ikatan organisasi. Contoh kelompok sosial antara lain kelompok teman atau kelompok kerabat. Secara sederhana, kelompok tani merupakan sekumpulan orang yang memliki kesamaankesamaan seperti berlatar belakang petani, kesamaan kebutuhan dan tujuan, serta kesamaan wilayah tempat tinggal. Kelompok tani juga mengatur upaya pemenuhan kebutuhan, pemecahan masalah dan pencapaian tujuan bersama.

\section{Analisis Pendapatan Usahatani}

Pendapatan atau keuntungan adalah selisih antara penerimaan dan semua biaya (Soekartawi, 2006). Analisis usahatani dapat dipakai untuk melihat seberapa besar keberhasilan kegiatan usahatani dan untuk tolak ukur untuk rancangan keadaan yang akan datang. Penerimaan usahatani adalah perkalian antara volume produksi yang diperoleh dengan harga jual (Soekartawi, 2006). Untuk menghitung pendapatan usahatani diperlukan dua keterangan pokok yaitu keadaan pengeluaran selama usahatani dijalankan dalam waktu yang ditetapkan dan keseluruhan penerimaan. Penerimaan usahatani adalah nilai uang yang diterima dari penjualan produk usahatani yang bisa berwujud tiga hal, yaitu hasil penjualan produk yang akan dijual, hasil penjualan produk sampingan, dan produk yang dikonsumsi rumah tangga selama melakukan kegiatan usahatani. 


\section{Analisis Keuntungan atas Biaya (B/C ratio)}

Menurut Soeharto (1997) B/C Ratio merupakan metode yang dilakukan untuk melihat berapa manfaat yang diterima oleh proyek untuk satu satuan matauang (dalam hal rupiah) yang dikeluarkan. B/C Ratio adalah suatu rasio yang membandingkan antara benefit atau pendapatan dari suatu usaha dengan biaya yang dikeluarkan. Sedangkan menurut Rahardi dan Hartono (2003) analisis B/C Ratio adalah perbandingan antara tingkat keuntungan atau pendapatan yang diperoleh dengan total biaya yang dikeluarkan. Suatu usaha dikatakan layak dan memberi manfaat

apabila nilai $\mathrm{B} / \mathrm{C}$ Ratio lebih besar dari nol (0), semakin besar nilai B/C Ratio maka semakin besar pula manfaat yang akan di peroleh dari usaha tersebut.

\section{Analisis Penerimaan atas Biaya (R/C ratio)}

Soeharjo dan Patong menyatakan bahwa rasio penerimaan atas biaya menunjukkan berapa besarnya penerimaan yang akan diperoleh dari setiap rupiah yang dikeluarkan dalam produksi usahatani. Rasio penerimaan atas biaya produksi dapat digunakan untuk mengukur tingkat keuntungan relatif kegiatan usahatani, artinya dari angka rasio penerimaan atas biaya tersebut dapat diketahui apakah suatu usahatani menguntungkan atau tidak. Menurut Marrisa (2010) tingkat pendapatan usaha dapat diukur mengunakan analisis penerimaan dan biaya ( $R / C$ Ratio) yang disarankan pada perhitungan secara finansial. Analisis ini menunjukkan besar penerimaan usaha yang akan diperoleh pengusaha untuk setiap rupiah biaya yang dikeluarkan untuk kegiatan usaha. Jika R/C Ratio bernilai lebih besar dari $1(\mathrm{R} / \mathrm{C}>1)$ artinya setiap tambahan biaya yang dikeluarkan akan menghasilkan tambahan penerimaan yang lebih besar daripada tambahan biaya atau secara sederhana kegiatan usaha menguntungkan. Bila nilai $\mathrm{R} / \mathrm{C}$ Ratio lebih kecil dari $1(\mathrm{R} / \mathrm{C}<1)$ artinya tambahan biaya yang dikeluarkan akan menghasilkan tambahan penerimaan yang lebih kecil dari tambahan biaya atau secara sederhana kegiatan usaha mengalami kerugian.

\section{Break Event Point (BEP)}

Analisis titik pulang pokok (break event point) adalah suatu alat analisis yang digunakan untuk mengetahui hubungan antara variabel di dalam kegiatan perusahaan, seperti luasan produksi atau tingkatan produksi yang dilaksanakan dengan biaya yang dikeluarkan, serta pendapatan yang diterima dari perusahaan. Pendapatan perusahaan merupakan penerimaan karena bersumber dari kegiatan perusahaan sedangkan biaya operasinya merupakan pengeluaran (Umar, 1997).

\section{METODE PENELITIAN}

\section{Lokasi dan Waktu Penelitian}

Penelitian ini dilakukan di kelompok 
Tani Jaya yang berlokasi di Desa Ciaruteun Ilir, Kecamatan Cibungbulang, Kabupaten Bogor. Pengumpulan data dilakukan pada bulan Agustus sampai dengan September 2013.

\section{Jenis dan Sumber Data}

Jenis data yang digunakan dalam penelitian ini adalah data primer dan sekunder. Data primer diperoleh dari peninjauan lansung ke lapangan dan wawancara lansung kepada petani di kelompok Tani Jaya Desa Ciaruteun Ilir yang menjadi responden. Data sekunder diperoleh dari berbagai literatur instansiinstansi yang terkait dengan permasalahan penelitian seperti Badan Pusat Statistika, Badan Pusat Penelitian dan pengembangan Hortikultura serta instansi terkait lainnya seperti kantor Dinas Pertanian Kabupaten Bogor dan Kantor Badan Penyuluh Pertanian, Perikanan, Perkebunan dan Kehutanan (BP4K) Kabupaten Bogor.

\section{Metode Pengolahan Data}

Pendapatan usahatani dibedakan menjadi dua, pertama pendapatan atas biaya tunai yaitu biaya yang benar-benar dikeluarkan oleh petani. Kedua, pendapatan atas biaya total dimana semua input milik petani juga diperhitungkan sebagai biaya. Pendapatan jenis pertama disebut pendapatan tunai. Pendapatan jenis kedua disebut pendapatan total. Analisis pendapatan usahatani dapat dinyatakan dalam persamaan sebagai berikut:

$$
\begin{aligned}
& \mu \text { tunai }=\mathrm{NP}-\mathrm{BT} \\
& \mu \text { total }=\mathrm{NP}-(\mathrm{BT}+\mathrm{BD})
\end{aligned}
$$

Dimana:

$$
\begin{array}{ll}
\mu & =\text { Pendapatan }(\mathrm{Rp}) \\
\mathrm{NP} & =\text { Nilai produk/penerimaan tunai }(\mathrm{Rp}) \\
\mathrm{BT} & =\text { Biaya tunai }(\mathrm{Rp}) \\
\mathrm{BD} & =\text { Biaya diperhitungkan }(\mathrm{Rp})
\end{array}
$$

Analisis $\mathrm{R} / \mathrm{C}$ ratio atau Return and Cost ratio $(\mathrm{R} / \mathrm{C}$ ratio) merupakan perbandingan antara nilai output terhadap nilai inputnya atau perbandingan antara penerimaan dan pengeluaran usahatani. Untuk mengetahui nilai $\mathrm{R} / \mathrm{C}$ ratio dilakukan penghitungan dengan menggunakan rumus:

$$
R / \text { r ratio }=\frac{\text { Jumlah Penerimaan }}{\text { Jumlah Biaya }}
$$

Jika :

$\mathrm{R} / \mathrm{C}$ Ratio $>1=$ usahatani menguntungkan

$\mathrm{R} / \mathrm{C}$ Ratio $<1=$ usahatani rugi

$\mathrm{R} / \mathrm{C}$ Ratio $=1=$ usahatani impas

Benefit and Cost ratio ( $\mathrm{B} / \mathrm{C}$ ratio) adalah tingkat keuntungan atau pendapatan yang diperoleh dengan total keseluruhan biaya yang dikeluarkan. Pada dasarnya suatu usaha dikatakan layak dan memberikan manfaat positif pada suatu usaha apabila nilai suatu B/C Ratio lebih besar dari nol (0) dan semakin besar suatu nilai B/C Ratio semakin besar pula manfaat positif yang akan diterima dalam suatu usaha tersebut (Rihardi, 2003: 6). Analisis $\mathrm{B} / \mathrm{C}$ Ratio dapat dihitung dengan rumus : 


$$
B / C \text { Ratio }=\frac{\text { Keuntungan }}{\text { Total Biaya Produksi }}
$$

Analisis titik impas atau Break Event Ponit (BEP) merupakan cara untuk mengetahui batas penjuala minimum agar suatu perusahaaan tidak menderita kerugian tetapi belum memperoleh laba atau laba sama dengan nol. Secara matematis analisis Break Event Point (BEP) dapat dihitung dengan rumus (Rochaeni dalam Zulfahmi, 2011) sebagai berikut:

$$
\begin{aligned}
& \text { BEP produksi }=\frac{\text { Total Biaya }}{\text { Harga Jual }} \\
& \text { BEP Harga jual }=\frac{\text { Total Biaya }}{\text { Total } \text { Produks } i}
\end{aligned}
$$

\section{HASIL DAN PEMBAHASAN}

\section{Biaya Produksi Usahatani}

Biaya usaha tani sayuran adalah seluruh komponen biaya yang dikeluarkan oleh seluruh petani yang menjadi anggota Kelompok Tani Jaya Desa Ciaruteun Ilir dalam menjalankan usaha tani sayuran. Biaya total yang dikeluarkan terdiri atas biaya tunai dan biaya yang diperhitungkan (biaya tidak tunai).

\section{Biaya Tunai (Out Of Pocket Cost)}

Biaya tunai dalam penelitian ini adalah seluruh biaya yang dikeluarkan petani dalam bentuk tunai untuk melakukan usahataninya selama tahun 2013 pada Kelompok Tani Jaya Desa Ciaruteun ilir. Biaya tunai dalam penelitian ini meliputi biaya pupuk organik, biaya pupuk anorganik, biaya pestisida, biaya kapur, biaya pengikat sayur, gaji tenaga kerja luar keluarga (TKLK), biaya pengairan dan bibit. Biaya tunai usahatani sayuran pada Kelompok Tani Jaya dapat dilihat pada tabel berikut:

Tabel 2 Rata-Rata Biaya Tunai Usahatani Sayuran Kelompok Tani Jaya Desa Ciaruteun Ilir Tahun 2013

\begin{tabular}{llr}
\hline NO & \multicolumn{1}{c}{ URAIAN } & $\begin{array}{r}\text { Biaya/Tahun/Petani } \\
(\mathrm{Rp})\end{array}$ \\
\hline 1 & TKLK & 7.706 .071 \\
2 & Pupuk Organik & 4.193 .214 \\
3 & Pupuk & 436.554 \\
& Anorganik & \\
4 & Pestisida & 535.506 \\
5 & Kapur & 2.619 .321 \\
6 & Irigasi & 288.393 \\
7 & Bibit & 437.018 \\
8 & Tali Bambu & 140.950 \\
\hline & & 16.357 .027 \\
\hline
\end{tabular}

Sumber: Data Primer, Diolah

\section{Biaya Diperhitungkan}

Biaya yang diperhitungkan dalam penelitian ini meliputi biaya tenaga kerja dalam keluarga (TKDK), biaya penyusutan peralatan, biaya sayuran yang dikonsumsi sendiri dan perhitungan sewa lahan sendiri.

Tabel 3 Rata-Rata Biaya Diperhitungkan Usahatani Sayuran Kelompok Tani Jaya Desa Ciaruteun Ilir 
Tahun 2013

\begin{tabular}{llr}
\hline NO & \multicolumn{1}{c}{ URAIAN } & $\begin{array}{r}\text { BIAYA/TAHUN/ } \\
\text { PETANI(Rp) }\end{array}$ \\
\hline 1 & Tenaga Kerja Dalam & $1.300 .000,00$ \\
& Keluarga & \\
2 & Penyusutan Peralatan & $587.068,46$ \\
3 & Sewa Lahan & $1.789 .285,71$ \\
4 & Konsumsi Keluarga & $335.477,68$ \\
\hline & Total & $4.011 .831,86$ \\
\hline
\end{tabular}

Sumber: Data Primer, Diolah

\section{Biaya Total}

Total biaya merupakan jumlah

keseluruhan modal kerja yang terdiri dari biaya tunai dan biaya diperhitungkan yang dikeluarkan dalam melakukan kegiatan usahatani sayuran.

Tabel 4 Rata-Rata Biaya Total Usahatani Sayuran Kelompok Tani Jaya Desa Ciaruteun Ilir Tahun 2013

\begin{tabular}{|c|c|c|}
\hline NO & JENIS BIAYA & $\begin{array}{c}\text { JUMLAH/TAHUN/ } \\
\text { PETANI (Rp) }\end{array}$ \\
\hline 1 & Biaya Tunai & 16.357 .027 \\
\hline 2 & $\begin{array}{l}\text { Biaya } \\
\text { Diperhitungkan }\end{array}$ & 4.011 .832 \\
\hline & TOTAL & 20.368 .859 \\
\hline
\end{tabular}

Sumber: Data Primer, diolah

\section{Pendapatan Usahatani Sayuran}

Penerimaan usahatani sayuran ini merupakan nilai produksi yang diperoleh dari hasil penjualan sayuran kelompok Tani Jaya. Berdasarkan hasil olahan data di lapangan penerimaan rata-rata yang diperoleh petani di Kelompok Tani Jaya Desa Ciaruteun Ilir adalah sebesar Rp. 60.954.875,-/tahun/petani dan untuk harga jual yang ditentukan untuk masing-masing sayuran bayam, kangkung, dan caisim berturut-turut adalah Rp. 5.500,-, Rp. 4000,-, Rp. 3.500,-. Harga jual usahatani sayuran di Kelompok Tani Jaya ini ditentukan oleh kelompok tani sebagai pengepul dari sayuran yang di produksi petani. Harga ini juga dipengaruhi oleh harga yang berlaku dipasaran. Penjualan sayuran di Desa Ciaruteun dihitung dengan satuan gabung yang masingsayuran berbeda-beda berat pergabungnya, berat bayam pergabung adalah $10 \mathrm{Kg}$, kangkung $12 \mathrm{Kg}$, dan caisim $9 \mathrm{Kg}$. Dari penjualan pergabung ini penulis menyetarakan ke satuan yang lebih umum dipakai yaitu kilogram. Untuk lebih jelas, penerimaan dari hasil penjualan sayuran bayam, kangkung, dan caisim dapat dilihat pada tabel 5.

\section{Keuntungan Usahatani Sayuran}

Analisis pendapatan di bagi dua, yaitu pendapatan atas biaya tunai dan pendapatan atas biaya total. Total keuntungan yang didapat petani dari usahatani sayuran adalah Rp.40.586.016,-/tahun/petani. Pendapatan usahatani sayuran ini telah cukup memadai karena pendapatan yang diperoleh telah cukup untuk membayar seluruh biaya pembelian sarana produksi termasuk 
seluruh komponen biaya administrasi yang melekat pada pembelian tersebut. Usahatani sayuran menurut penulis dan didukung data serta analisis memang sudah pantas dikatakan berhasil karena penerimaan yang di peroleh sudah mencukupi untuk membayar seluruh biaya yang dikeluarkan setiap petani selama masa tanam baik tunai maupun yang diperhitungkan dan masih menghasilkan selisih yang signifikan antara pengeluaran dan pemasukan berupa laba/ keuntungan. Analisis pendapatan usahatani sayuran di Kelompok Tani Jaya dapat di lihat pada Tabel 6.

Tabel 5 Rata-Rata Penerimaan Usahatani Sayuran Kelompok Tani Jaya Desa Ciaruteun Ilir Tahun 2013

\begin{tabular}{|c|c|c|c|c|}
\hline No & Sayuran & $\begin{array}{c}\text { Harga/ } \\
\mathrm{Kg} \\
(\mathrm{Rp})\end{array}$ & $\begin{array}{l}\text { Produksi/ } \\
\text { Tahun/ } \\
\text { Petani } \\
\text { (Kg) }\end{array}$ & $\begin{array}{l}\text { Penerimaan } \\
\text { /Tahun } \\
\text { /Petani (Rp) }\end{array}$ \\
\hline 1 & Bayam & 5.500 & $4.319,00$ & 23.754 .500 \\
\hline 2 & Kangkung & 4.000 & $6.417,00$ & 25.668 .000 \\
\hline 3 & Caisim & 3.500 & $3.294,96$ & 11.532 .375 \\
\hline \multicolumn{4}{|c|}{ TOTAL } & 60.954 .875 \\
\hline
\end{tabular}

Sumber: Data Primer, diolah

Tabel 6 Rata-Rata Keuntungan Usahatani

Sayuran Kelompok Tani Jaya

Desa Ciaruteun Ilir Tahun 2013

\begin{tabular}{lc}
\hline No Uraian & Nilai/Tahun/ \\
& Petani (Rp) \\
\hline
\end{tabular}

\begin{tabular}{llr}
\hline 1 & Penerimaan & 60.954 .875 \\
2 & Biaya Tunai & 16.357 .027 \\
3 & Biaya Diperhitungkan & 4.011 .832 \\
4 & Biaya Total & 20.368 .859 \\
& Keuntungan Atas Biaya & \\
5 & Tunai & 44.579 .848 \\
& Keuntungan Atas Biaya & \\
6 & Total & 40.586 .016 \\
\hline
\end{tabular}

Sumber: Data primer, diolah

\section{Analisis Rasio Penerimaan Atas Biaya (R/C Ratio)}

Keuntungan relatif dari usahatani sayuran ini dapat di hitung dengan menggunakan analisis $\mathrm{R} / \mathrm{C}$ ratio. Nilai $\mathrm{R} / \mathrm{C}$ ratio adalah perbandingan antara penerimaan dengan biaya produksi. Analisis rasio dalam penelitian ini dibedakan menjadi

dua bagian yaitu $\mathrm{R} / \mathrm{C}$ ratio atas biaya tunai dan $\mathrm{R} / \mathrm{C}$ ratio atas biaya total. Analisis $\mathrm{R} / \mathrm{C}$ ratio usahatani sayuran di Kelompok Tani Jaya dapat dilihat pada tabel berikut.

Tabel 7 Analisis Rasio Penerimaan Atas Biaya (R/C Ratio) Usahatani Sayuran Kelompok Tani Jaya Desa Ciaruteun Ilir Tahun 2013

\begin{tabular}{clc}
\hline No & \multicolumn{1}{c}{ Uraian } & Nilai (Rp) \\
\hline 1 & Penerimaan & 60.954 .875 \\
2 & Biaya Tunai & 16.357 .027 \\
3 & Biaya Diperhitungkan & 4.011 .832 \\
\hline
\end{tabular}




\begin{tabular}{clr}
\hline 4 & Biaya Total & 20.368 .859 \\
5 & $\begin{array}{l}\text { R/C Biaya Ratio Atas } \\
\text { Biaya Tunai }\end{array}$ & 3,73 \\
& R/C Ratio Atas Biaya & \\
6 & Total & 2,99 \\
\hline
\end{tabular}

Sumber: Data primer, diolah

Berdasarkan tabel 7 dapat dilihat bahwa nilai $\mathrm{R} / \mathrm{C}$ ratio atas biaya tunai sebesar 3,73. Hal ini berarti setiap Rp. 1.000,- biaya yang dikeluarkan Kelompok Tani Jaya dalam menjalankan usahatani sayuran akan memberikan penerimaan sebesar 3.730. Sedangkan nilai $\mathrm{R} / \mathrm{C}$ ratio atas biaya total diperoleh sebesar 2,99 yang mengindikasikan bahwa setiap Rp. 1.000,atas biaya keseluruhan yang dikeluarkan akan memberikan penerimaan sebesar Rp. 2.990,- kepada petani pengusaha sayuran di Kelompok Tani Jaya.

\section{Analisis Ratio Keuntungan Atas Biaya (B/C Ratio)}

Perbandingan antara pendapatan yang diperoleh dengan biaya yang dikeluarkan dalam menjalankan usahatani sayuran di Kelompok Tani Jaya ini merupakan analisis yang di gunakan untuk melihat tingkat nilai pendapatan yang diperoleh dari setiap rupiah yang dikeluarkan. Nilai $\mathrm{B} / \mathrm{C}$ ratio yang digunakan pada analisis ini meliputi nilai $\mathrm{B} / \mathrm{C}$ ratio atas biaya tunai dan nilai $\mathrm{B} / \mathrm{C}$ ratio atas biaya total. Komponen ratio keuntungan atas biaya pada usahatani sayuran pada Kelompok Tani Jaya dapat dilihat pada tabel di bawah ini :
Tabel 8 Analisis Ratio Keuntungan Atas Biaya (B/C Ratio) Usahatani

Sayuran Kelompok Tani Jaya Desa Ciaruteun Ilir Tahun 2013

\begin{tabular}{llr}
\hline No & \multicolumn{1}{c}{ Uraian } & \multicolumn{1}{c}{ Nilai (Rp) } \\
\hline 1 & Penerimaan & 60.954 .875 \\
2 & Biaya Tunai & 16.357 .027 \\
3 & Biaya Diperhitungkan & 4.011 .832 \\
4 & Biaya Total & 20.368 .859 \\
5 & $\begin{array}{l}\text { Keuntungan Atas Biaya } \\
\text { Tunai }\end{array}$ & 44.579 .848 \\
& $\begin{array}{l}\text { Keuntungan Atas Biaya } \\
\text { Total }\end{array}$ & 40.586 .016 \\
7 & $\begin{array}{l}\text { B/C Biaya Ratio Atas Biaya } \\
\text { Tunai }\end{array}$ & 2,73 \\
& B/C Ratio Atas Biaya Total & 1,99 \\
\hline
\end{tabular}

Sumber: Data primer, diolah

Nilai B/C ratio adalah perbandingan antara keuntungan dengan biaya produksi. Berdasarkan keuntungan dan biaya yang dikeluarkan, nilai $\mathrm{B} / \mathrm{C}$ ratio atas biaya tunai adalah 2,73, artinya setiap Rp. 1.000,untuk biaya tunai akan menghasilkan keuntungan sebanyak Rp. 2.730,-- B/C ratio atas biaya total yang diperoleh adalah sebesar 1,99. Hal ini menunjukkan bahwa dengan $\mathrm{B} / \mathrm{C}$ ratio sebesar 1,99 berarti untuk setiap penambahan biaya total sebesar Rp. 1000,-, maka usahatani sayuran Kelompok Tani Jaya Ciaruteun Ilir akan memperoleh keuntungan atau pendapatan sebesar Rp. 1.990,-. Untuk perhitungan B/C Ratio, sesuai dengan teori Rahardi dan Hartono 
bahwa suatu usaha dikatakan layak dan memberikan manfaat apabila nilai $\mathrm{B} / \mathrm{C}$ lebih besar dari nol $(\mathrm{B} / \mathrm{C}>0)$. Semakin besar nilai $\mathrm{B} / \mathrm{C}$ maka semakin besar nilai manfaat yang akan diperoleh dari usaha tersebut. Dari hasil perhitungan nilai B/C ratio usahatani sayuran Kelompok Tani Jaya Ciaruteun Ilir tersebut maka dengan kata lain $\mathrm{B} / \mathrm{C}>0$ hal ini berarti bahwa usahatani sayuran di Kelompok Tani Jaya dapat memberikan manfaat atau menguntungkan dan layak untuk dilanjutkan.

\section{Analisis Break Even Point (BEP)}

Dalam menentukan titik impas (BEP) produksi perlu diketahui biaya produksi total dan penerimaan total sedangkan untuk menentukan harga minimal yang harus

ditentukan petani diperlukan biaya total dan harga jual masing-masing sayuran. Semua itu dirangkum dalam tabel di bawah ini:

Tabel 9 Analisis Break Event Point (BEP) Usahatani Sayuran Kelompok Tani Jaya Desa Ciaruteun Ilir Tahun 2013

\begin{tabular}{llrrr}
\hline \multirow{2}{*}{ No } & Uraian & \multicolumn{3}{c}{ Jumlah } \\
\cline { 3 - 5 } & & Bayam & Kangkung & Caisim \\
\hline \multirow{2}{*}{1} & $\begin{array}{l}\text { Volume } \\
\text { Produksi (Kg) }\end{array}$ & 4.319 & 6.417 & 3.295 \\
& $\begin{array}{l}\text { Biaya Total } \\
\text { (000 Rp) }\end{array}$ & $7.45,6$ & $6.119,8$ & $5.947,4$ \\
& $\begin{array}{l}\text { Harga Jual } \\
\text { (Rp) }\end{array}$ & 5.500 & 4.000 & 3.500 \\
\hline
\end{tabular}

\begin{tabular}{lllll}
\hline 4 & $\begin{array}{l}\text { BEP Volume } \\
\text { Produksi (Kg) }\end{array}$ & 1.356 & 1.530 & 1.699 \\
& $\begin{array}{l}\text { BEP Harga } \\
5\end{array}$ & 1.726 & 954 & 1.805 \\
\hline
\end{tabular}

Sumber: Data primer, diolah

Hasil diatas menunjukan bahwa nilai BEP rata-rata yang di peroleh petani pada usahatani sayuran Kelompok Tani Jaya Ciaruteun Ilir adalah BEP produksi bayam $1.356 \mathrm{Kg}$, kangkung $1.530 \mathrm{~kg}$, dan caisim $1.699 \mathrm{~kg}$ serta BEP harga untuk bayam Rp. 1.726,-, kangkung Rp. 954,-, dan caisim Rp. $1.805,-$. Semua hasil itu menunjukan bahwa usahatani sayuran tersebut tidak untung dan tidak rugi pada level tersebut. usaha tersebut baru akan mulai mendapat keuntungan jika output lebih besar dari nilai BEP produksi dan harga hasil perhitungan diatas. Usahatani sayuran mendapat keuntungan dari selisih produksi yang dihasilkan dari total produksi rata-rata masing-masing untuk bayam 2.963,39 $\mathrm{kg} /$ petani, kangkung 4.887,05 kg/petani, dan caisim 1.595,69 kg/petani. Sedangkan selisih keuntungan harga yang didapatkan petani masing-masing adalah bayam $\mathrm{Rp}$. 3.774,-/kg, kangkung Rp. 3.046,-/kg, dan Rp. $1.695,-/ \mathrm{kg}$.

\section{KESIMPULAN DAN SARAN}

\section{Kesimpulan}

1. Pendapatan usaha tani sayuran kelompok Tani Jaya Desa Ciaruteun Ilir tahun 2013 mencapai Rp. 1.706.736.500.-/tahun dengan luas areal 16,7 $\mathrm{Ha}$ dan jumlah anggota 
kelompok tani 28 orang atau setara dengan Rp. 3.649.993,/Ha/tahun/petani.

2. Nilai $\mathrm{R} / \mathrm{C}$ rasio atas biaya total sebesar 2,99 dan nilai B/C ratio atas biaya total sebesar 1,99. Dengan nilai $\mathrm{R} / \mathrm{C}$ ratio atas biaya total sebesar 2,99 dan B/C ratio atas biaya total sebesar 1,99 menunjukan bahwa kondisi usahatani sayuran ini layak untuk dijalankan dan memiliki prospek yang bagus untuk dikembangkan.

3. BEP produksi dari produksi total bayam $37.957 \mathrm{Kg}$, kangkung 42.839 $\mathrm{kg}$, dan caisim $47.580 \mathrm{~kg}$ serta BEP harga untuk bayam Rp. 1.726,-, kangkung Rp. 954,-, dan caisim Rp. $1.805,-$. Usahatani sayuran mendapat keuntungan dari selisih produksi yang dihasilkan dari total produksi masingmasing untuk bayam $82.975 \mathrm{~kg}$, kangkung 136.837, dan caisim 44.679 kg. Sedangkan selisih keuntungan harga yang didapatkan petani masingmasing adalah bayam Rp. 3.774,-/Kg, kangkung Rp. 3.046,-/Kg, dan caisim Rp. $1.695,-/ \mathrm{Kg}$.

4. Berdasarkan hasil perhitungan pendapatan, R/C Rasio, B/C Rasio, dan Break Even Point (BEP). Dengan R/C $>1, \mathrm{~B} / \mathrm{C}>0$ serta $\mathrm{BEP}$ produksi di bawah produksi real dan BEP harga dibawah harga real maka dapat diketahui bahwa usahatani sayuran ini layak untuk dijalankan dan memiliki prospek usaha yang bagus untuk dikembangkan.

\section{Saran}

Berdasarkan kesimpulan di atas, ada beberapa saran yang penulis ajukan untuk petani di Kelompok Tani Jaya.

1. Data hasil penelitian menunjukkan bahwa usahatani sayuran di kelompok Tani Jaya ini sangat menguntungkan dan efektif, hal tersebut juga menunjukkan bahwa usahatani sayuran ini mempunyai prospek yang bagus untuk dikembangkan dengan cara penambahan luas area tanam. Dengan bertambahnya luas areal serta pengelolaan yang bagus akan meningkatkan produksi dan diikuti dengan bertambahnya pendapatan petani.

2. Disarankan ada pelatihan manajemen yang baik terhadap para anggota kelompok tani. Baik itu pelatihan mengenai teknis usahatani maupun non teknis seperti pelatihan menganalisis usahatani dengan baik. Hasil analisis ini bisa dimanfaatkan untuk pengembangan usahatani terutama untuk mendapatkan pembiayaan dari lembaga peminjam modal.

\section{DAFTAR PUSTAKA}

Almatsier, S, 2004. Prinsip Dasar Ilmu Gizi. Jakarta: PT. Gramedia Pustaka Umum.

Ashari, S. 1995. Hortikultura Aspek Budidaya. Jakarta: UI Press

Badan Pusat Statistika. 2012. Penduduk 15 Tahun Ke Atas yang Bekerja Menurut 
Lapangan Pekerjaan 2004-2012. Jakarta: BPS.

Bandini. 2001. Bayam. Jakarta: Penebar Swadaya.

Departemen Pertanian. 2007. Pedoman Penumbuhan dan Pengembangan kelompok Tani dan Gabungan Kelompok Tani. Jakarta: Kementan

Dirjen Tanaman Hortikultura. 2012. Pedoman Umum Pelaksanaan Pengembangan Hortikultura 2012. Jakarta: Kementan.

Fadholi, Hernanto.1993. Ilmu Usaha Tani. Jakarta: Penebar Swadaya.

Hadisoeganda, A. Widjaja W. 1996. Bayam Sayuran Penyangga Petani di Indonesia. Monograf No. 4. Bandung: BPPP

Herlianto, Didit dan Triani Pujiastuti. 2009. Studi Kelayakan Bisnis. Yogyakarta: Graha Ilmu.

Hernanto, F. 1993. Ilmu Usahatani. Cetakan Ketiga (Jakarta: Penebar Swadaya)

Husein, Umar. 2003. Metode Riset Bisnis. Jakarta: PT Gramedia Pustaka Utama.

Kasmir dan Jakfar. 2007. Studi Kelayakan Bisnis. Jakarta: Penerbit PT. Persada Media.

Kasmir dan Jakfar. 2007. Studi Kelayakan Bisnis edisi kedua. Jakarta: Kencana

Kementrian Pertanian. 2011. Rekapitulasi Konsumsi Perkapita Sayuran dan Buah. Jakarta: Dirjen Hortikultura.
Mahekam, J.P. dan R. L. Malcom. 1991. Manajemen Usahatani Daerah Tropis. Diterjemahkan oleh Basilius B. Teuku (Jakarta: LP3ES)

Mardikanto T. Penyuluhan Pertanian. (Surakarta: Sebelas Maret University Press, 1993).

Marsudi, Edy. 2010. The Analysis of The Income at Some Vegetables Farm at Pidie Regency Jurnal Agrisep Vol 11 No.2. Fakultas Pertanian Universitas Syiah Kuala. Darussalam Banda Aceh.

Opena, R. T and D.C. S Tay. 1994. Brassica rapa L. Group Caisim.

Rahardi dan Hartono. 1993. Agribisnis Peternakan (Jakarta: Penebar Swadaya)

Rihardi, F. Palungkun, Rony. Budiarti, Asiani. 1993. Agribisnis Tanaman Sayuran. (Jakarta: Penebar Swadaya)

Rahim. Abd. dan. Hastuti. DRW. 2007. Ekonomi Pertanian. Penebar Swadaya, Jakarta.

Redaksi Trubus. 2010. Bertanam Sayur dalam Pot. Cet Ke-XIX (Jakarta: Penebar Swadaya)

Rasahan, C.A. 1997. Pembangunan Tanaman Pangan dan Hortikultura Pada Awal Abad 21. Pustaka Sinar Harapan: Malang

Soeharjo dan Patong. 1973. Sendi-sendi Pokok Usahatani. Jurusan Ilmu-ilmu Sosial Ekonomi Pertanian. Fakultas Pertanian. Bogor: Institut Pertanian Bogor. 
Soeharjo dan Patong. 1991. Ilmu Usahatani. Bogor. Departemen IlmuIlmu Sosial Ekonomi Institut Pertanian Bogor.

Soeharto, Iman. 1993. Manajemen Proyek: Dari Konseptual Sampai Operasional (Jakarta: Erlangga)

Soeharto, Iman. 1997. Manajemen Proyek (Jakarta: Erlangga)

Soekartawi. 1986. Ilmu Usahatani dan Pengembangan Petani Kecil (Jakarta: UI-Press)

Soekartawi. 2002. Prinsip Dasar Ekonomi Pertanian. Jakarta. Rajagrafindo Persada.

Soekartawi. 2006. Analisis Usaha Tani. Jakarta: UI Press.

Soetriono. 2003. Pengantar Ilmu Pertanian. Malang: Bayu Media
Suhardiyono., 1992. Penyuluhan,Petunjuk Bagi Penyuluh Pertanian (Jakarta: Erlangga)

Sumoprastowo., 2000. Memilih dan Menyimpan Sayur Mayur, Buah Buahan dan Bahan Makanan, Bumi Aksara. Jakarta.

Suratiyah. 2006. Ilmu Usahatani. Penebar Swadaya. Jakarta.

Sutarno, H. 1995. Pedoman Bertanam Sayuran Dataran Rendah. Gadjah Mada University Press. Yogyakarta.

Sutojo, Siswanto. 2000. Studi Kelayakan Proyek. Jakarta: PT Damar Mulia Pustaka.

Umar, Husein. 1997. Studi Kelayakan Bisnis. Edisi 2 (Jakarta: Gramedia Pustaka Utama)

\footnotetext{
* Alumni Prodi Agribisnis dan ** Dosen Fakultas Sains dan Teknologi UIN Syarif Hidayatullah Jakarta
} 
